\title{
A construção dos heróis e a memória nacional entre os não letrados'
}

Marlene Cainelli ${ }^{2}$

\section{RESUMO}

Pretende-se neste artigo discutir as imp̨licações acerca das análises sobre memória e a constituição dos heróis nacionais. Tendo como pressuposto os estudos sobre o ensino de história e a construção da memória nacional, pretendemos levantar algumas questões relativas a presença dos ícones da história nacional entre pessoas que não freqüentaram a escola formal. Nessa pesquisa entrevistamos mulheres de um curso de alfabetizaçăo popular, sobre a figura de Tiradentes (feriado nacional) e outras festas cívicas, sendo que Tiradentes é considerado por muitos historiadores como presente na memória coletiva da nação como um herói nacional.

Palavras-chave: ensino de história, memória, educação popular

Ainda hoje o martírio de Joaquim José da Silva Xavier, o Tiradentes, toca os corações dos brasileiros, o que mostra a força simbólica desse personagem. ${ }^{3}$

O fato da autora desta frase direcionar a todos os brasileiros algum conhecimento em relação a figura de Tiradentes, leva-nos a pensar sobre as representações possíveis da memória nacional e quais seriam os brasileiros que compartilhariam de sentimentos sobre o martírio de Tiradentes. Para tanto começamos a refletir primeiramente sobre o conceito de brasileiro que é utilizado em frases deste tipo, que serve para exteriorizar o significado de povo e demonstrar o alcance da memória coletiva.

1 Este artigo é parte da Tese de Doutorado intitulada: História do Brasil, histórias de Brasileiros: história, passado e identidade na memória popular, defendida no Programa de pós-Graduação em História, UFPR en 2003.

2 Professora de Metodologia do Ensino de história - Universidade Estadual de Londrina,Professora do programa de Mestrado em Educação.

3 FonSECA, Thais Nívea. A imagem do Herói.In. Nossa História. Anoi/n³ 2, 2004, p.81 
No presente artigo trabalharemos com as representações sobre a História do Brasil que possuem pessoas que não tiveram acesso à escola formal, pois nosso objetivo é descobrir se a extensão de colocações como a citada acima, indicaria que a figura do mártir teria tido a força de construção de um herói nacional para todos os brasileiros.

Com relação aos adultos que não foram a escola acreditamos que a forma como entendem a história do Brasil aparecem nas concepções sobre o mundo, o espaço, o tempo, a sociedade em que vivem e que a força dessas representações estão ancoradas nas memórias transmitidas pela tradição oral. As relações que os indivíduos estabelecem com o social, o histórico e o cultural são na verdade a memória, aquilo que é salvo do esquecimento, pelas gerações, pelos grupos, segundo Halbwachs ${ }^{4} . .$. nossas lembranças permanecem coletivas, e elas nos são lembradas pelos outros, mesmo que se trate de acontecimentos nos quais só nós estivemos envolvidos, e com objetos que só nós vimos. É porque, em realidade, nunca estamos só.

Para direcionar a pesquisa $a^{5}$ que fizemos e tentar perceber como é entendida a história do Brasil por aqueles que não freqüentaram a escola, optamos por questionar os entrevistados sobre produções históricas veiculadas, pela mídia, pelas festas cívicas, que são representantes daquilo que entendemos como história nacional.

Os pesquisadores que estudam as relações que se estabelecem entre concepções sobre a história do Brasil com a produção do imaginário do brasileiro, apontam para a existência de imagens recorrentes nas divulgações históricas, sejam através de livros didáticos, paradidáticos, jornais, revistas, cinema, televisão, essas imagens foram então definidas como canônicas. Elias Tomé Saliba assim as conceitua:

...Seriam aquelas imagens - padrão ligadas a conceitos chaves de nossa vida social e intelectual. Tais imagens constituem pontos de referência inconscientes, sendo, portanto, decisivas em seus efeitos subliminares de identificação coletiva. São imagens de tal forma incorporadas em nosso imaginário coletivo, que as identificamos rapidamente. ${ }^{6}$

\footnotetext{
I HALBWACHS, Maurice. A memória coletiva, São Paulo, Vértice, 1990, p.26 Neste artigo apresentamos um fragmento da pesquisa realizada.
} 
Sabemos de antemão que essas imagens ditas canônicas, são em sua maioria veiculadas em livros didáticos, quadros, e outros elementos da cultura letrada, no entanto, segundo alguns autores a disseminação dessas imagens não se traduziria apenas no momento de sua confecção ou no artefato onde ela aparece, no caso o livro ou a escola, e sim disseminaria-se pelo imaginário coletivo, criando imagens orais, que seriam transmitidas pela descrição dos quadros, das figuras, nosso objetivo seria,então, perceber se o traçado construído por estas imagens, atingiria aquelas pessoas que nunca foram a escola.

Selecionamos então representações sobre a história do Brasil, algumas traballhadas na educação formal reproduzidas infinitamente nos livros didáticos e outras repetidas nas festas cívicas e nos feriados nacionais: Tiradentes (Inconfidência Mineira) Descobrimento do Brasil, Independência do Brasil e Escravidão. As três primeiras temáticas ganham força pelo fato de que as comemorações através do marco fundador de sua criação construírem um passado para nação, inquestionável e único, é o que se aprende por história do Brasil não apenas na escola mas também fora dela, em espaços públicos que ganham os nomes dos heróis nacionais como as praças, os bairros as ruas e principalmente nos calendários que figuram em vermelho a data a ser comemorada e na mídia que dedica o dia a reiterar o passado glorioso reafirmando-o todos os anos.

O ícone canônico nacional escolhido para trabalharmos neste texto é a figura de Tiradentes, por expressar no feriado de 21 de abril, uma das datas com maior repercussão escolar e fora dela 7 .Tiradentes é ainda uma das figuras mais representativas do projeto de construção da nação consolidado pelos republicanos. Sem dúvida alguma a transformação de Tiradentes em herói republicano é um dos temas recorrentes de qualquer análise historiográfica sobre a construção da naç̃̃o pós Império no Brasil. 021 de abril foi se tornando um lugar de memória indicativo das disputas pelas imagens e mitos que representariam a nação brasileira a partir da independência.

Alguns autores argumentam que a transformação de Tiradentes em herói

6 SALIBA, Elias Tomé. As imagens canônicas e o ensino de História. IN.SCHIMDT, Maria Auxiliadora e CAINELLI, Marlene Rosá. III Encontro Perspectivas do Ensino de História. Curitiba. Aos QuatroVentos, 1999. P. 437

7 Taús Níveá Fonseca, João Pinto Furtado, José Murilo de Carvalho, Noé Sandes e outros autores argumentam em vários trabalhos a construção da imagem de Tiradentes como herói nacional. 
nacional, não configuraria um projeto apenas republicano, também a monarquia, na tentativa de criar uma unidade para a nação brasileira depois da proclamação da independência, teria recorrido a estes projetos de unificação de um país que ainda não existia. 0 que havia era um território marcadamente fragmentado pelo estilo administrativo desde a colônia, com mercados regionais, sem rotas comerciais de integração que permitissem um comércio nacional, sem unidade política ou linguiística. A conquista de uma unidade nacional é então alvo de diversos projetos entre eles a construção de símbolos e mitos que a legitimasse.

A primeira celebração do 21 de abril ocorreu no Rio de Janeiro em 1881, desde 1866 haviam já sido erguidos monumentos em Minas Gerais em sua homenagem. O dia 21 de abril foi declarado feriado nacional em $1890^{8}$. Uma das construções sobre a imagem de Tiradentes, que nos interessa neste trabalho por marcar a idéia de identidade entre a construção do mito e sua legitimidade perante a população, é a aproximação da imagem do mártir com a de Jesus Cristo. Na peça teatral de Castro Alves Gonzaga ou a Revolução de Minas, escrita em 1867, Tiradentes já aparece com a imagem vinculada a de Cristo,

Ei-lo, o gigante da praça/0 Cristo da multidão!?É Tiradentes quem passa.../ Deixem passar o Titão."

Como fizemos a opção por perguntar as entrevistadas sobre a figura de Tiradentes tínhamos em mente que a figura apresentada em manuais didáticos, em celebrações nos meios de comunicação, teria de alguma forma marcado a memória das mulheres que entrevistamos, tendo como ponto de partida que a idealização da imagem de Tiradentes como a do Cristo crucificado, permitiria muito facilmente sua identificação com os sofredores, os mártires, heróis que morrem por uma causa, no caso de Tiradentes a morte pela nação brasileira.

A poderosa simbologia do Cristo em um país marcadamente cristão facilitaria a projeção de sua figura como herói, qualquer pessoa que visse uma imagem do Cristo crucificado, imediatamente o relacionaria com Tiradentes. Além da figura física outras aproximações foram realizadas para cristalizar as semelhanças entre a morte de Tiradentes e de Jesus Cristo, José Murilo de

8 CARVAlHO,José Murilo. A formação das Almas São Paulo, Companhia das Letras, 1990, p. 64

9 CARValHo, José Murilo, op cit. p.60 
Carvalho ao referir-se a construção dessa simbologia menciona 0 artigo de Luis Gama, publicado no primeiro número do jornal comemorativo do 21 de abril editado pelo Clube Tiradentes (1882), o título do artigo À forca o Cristo da Multidão... A forca é equiparada a cruz, o Rio de janeiro a Jerusalém, o Calvário ao Rocio. ${ }^{10}$

o Tema da consirução da identidade nacional é recorrente nos projetos políticos brasileiros. Aescrita da história da nação sempre esteve desde a independência no centro destas discussões. Tais vínculos entre os projetos de unidade nacional e a escrita da história produziram o que aqui chamamos de ícones da história nacional, e Tiradentes sempre esteve entre os heróis fundamentais de construção de uma identidade nacional. Seja nos livros de história ligados ao Instituto Histórico Geográfico Brassileiro, pós - proclamaação da República, encarregados de difundir a s imagens da nação republicana, seja os livros didáticos que desde os anos 30 do século XX, instituiu a consagraçãa dos heróis nacionais através da valorização dos seus feitos pelo páís e até os livros didáticos pós ditadura militar que difundem e reforçam a consagração dos mitos como o de Tiradentes, como podemos observar no relato de um Livro didático de 1997,

Só Tiradentes, o único que não era rico nem fazia parte da elite, foi enforcado e seu corpo cortado em pedaços: a cabeça ficou em Vila Rica es membros foram colocados em postes, na estrada que liga Minas Gerais ao Rio de Janeiro. A casa em que morava foi destruída e sobre a terra jogou-se sal, para que nem as plantas ali crescessem. Apesar de todas as atrocidades, a chama da liberdade que Tiradentes ascendeu não se apagou. Haveria ainda outras lutas, até que o sonho de independência dos inconfidentes se tornasse realidade. ${ }^{.1}$

O trecho acima não deixa dúvidas do posicionamento do autor sobre a temática da Inconfidência Mineira e sua representatividade para a história da nação. É a partir dos desdobramentos da inconfidência que torna-se realidade a independência do Brasil. Seria possível que a fixação das imagens sobre Tiradentes tivessem criado uma memória coletiva sobre ele, que um desdobramento intenso haveria possibilitado a circulação dessas imagens pela

\footnotetext{
${ }^{10}$ idem, p.61

1 PILETTI, Nelson e PILETTI, Claudino, História e Vida. 11ª ed. São Paulo, Ática, 1997, p.110
} 
sociedade criando uma memória sobre o mártir, mesmo para aqueles que nunca frequientaram os bancos escolares?

Nas entrevistas realizadas para esta pesquisa ${ }^{12}$ podemos observar que as respostas sobre Tiradentes, nos levam a outros desdobramentos sobre a construção do imaginário nacional. Perguntamos a dona ${ }^{13}$ Margarida sobre 0 dia 21 de abril, primeiro se ela sabia que era feriado?

Sei sim. É bom é sempre no meio da semana. A senhora sabe porque é feriado? Não, não sei.

Refiz a pergunta, tentando ajudar Dona Margarida, tentando que ela estabelecesse alguma relação entre o Feriado e a figura de Tiradentes. Perguntei a ela se nunca ouvira falar de Tiradentes ou se tinha visto alguma imagem dele?

Não, nunca ouvi falar dele. Ele tirava dentes? Era dentista?

Dona Maria de Lourdes também sabia que a data era feriado. Perguntei se ela sabia porque era feriado? Ela respondeu prontamente: Dia de Tiradentes.

Perguntei se ela sabia quem fora Tiradentes: Se já vira alguma imagem dele: Sei, foi o governo. Era do governo, morreu pelo governo. Era barbudo que nem Jesus.

Dona Nadir também sabia que era feriado. E também sabia que era dia de Tiradentes. Perguntei a ela o que sabia de Tiradentes: Sei que ele morreu enforcado.

Perguntei a ela se ela sabia o motivo do enforcamento e se já vira alguma imagem dele e onde: Ele morreu enforcado pelo descobrimento. Não conbeço nenbuma imagem não.

Dona Neuza também sabia do feriado, e que era o dia de Tiradentes.

Perguntei se ela sabia alguma coisa de Tiradentes: Não sei porque é feriado no dia dele nãa. Ele tira dentes não é. Eu sei que enira um negócio de dente, mais eu nãa sei não.

\footnotetext{
${ }^{12}$ Nesta pesquisa entrevistamos 7 mulheres que freqüentavam um curso de alfabetização oferecido por uma organização não governamental. Foram selecionadas muiheres que tinham ido a escola formal pelo período inferior a um ano durante toda sua vida.

13 .Mantivemos a expressão "dona" antes dos nomes, pois as senhoras entrevistadas foram assim tratadas durante todas as entrevistas.
} 
Dona Tereza sabia do feriado e que era dia de Tiradentes, mas também não sabia nada sobre ele, respondeu apenas que não sabia nada.

Dona Ermelinda respondeu prontamente que 21 de abril era dia de Tiradentes, no entanto, também não sabia nada sobre ele, nem quem fora, tão pouco o que fizera para que no seu dia fosse feriado. Perguntei a ela se nunca tivera curiosidade para saber porque é feriado no dia 21 de abril, no que ela respondeu:

É o governo que diz que éferiado, então ele deve ser alguém do governo não é? Mas eu nunca tive curiosidade não. Apenas é feriado eé bom quando é dia de semana e agente não precisaa ir trabalhar.

Dona Izaudite, sabia do feriado e que era dia de Tiradentes. Sobre o feriado e sobre o conhecimento dela de Tiradentes respondeu:

Quando chega perto das datas de comemorar Dona Cida ${ }^{14}$, ela manda a gente fazer um trabalho, para explicar, todas as datas a gente faz um trabalho. Tiradentes foi herói, era igual a Jesus Cristo e morreu também para nos salvar.

Perguntei a ela onde soubera disso. E se ela sabia mais alguma coisa e Tiradentes havia nos salvado do que?

Dona Izaudite respondeu que tinha sido o neto que falara, e que Dona Cida havia pedido para fazer o trabalho, como não sabia ler direito perguntou ao neto. Porque ele salvou a gente eu não sei não, não me lembro. Mas sei que ele morreu na cruz como Jesus. Cruz não, enforcado, cruz foi Jesus, mas foi tudo igual não foi?

$\mathrm{Na}$ fala de Dona Izaudite um pequeno vestígio de uma possível circularidade de uma história socializada pela escola, pois o neto que está na escola e a educadora popular foram os mencionados como locus do saber sobre o tema. As referências guardadas pela depoente tiveram na imagem de Cristo a única lembrança, uma relação também buscada pelos precursores da idealização de Tiradentes como herói.

\footnotetext{
${ }^{4}$ Dona Cida é a educadora popular que atua no projeto de alfabetização.
} 
As comemorações de 21 de abril não representam para essas mulheres uma data nacional ou motivo de comemorações, são referencias que passam desapercebidas, algumas das explicações dadas por elas para a data, resvalam na história didatizada, respondem sem significado que dia 21 é dia de Tiradentes, mesmo que não saibam o porquê da comemoração. Ele morreu enforcado, tem relação com o governo. São indícios de uma possível circulação dessa história da nação e constante tentativa de refundação de sua memória.

Diríamos que o desconhecimento sobre a figura de Tiradentes como herói da República, significou que o projeto republicano teve como objetivo atingir apenas os letrados através da escola. 0 feriado nacional é comemorado por todos os brasileiros no momento em que não vão ao trabalho, o comércio é fechado, as escolas e repartições públicas não funcionam. Este momento torna todos unos em um só movimento o de feriado nacional.

No entanto, a compreensão dos motivos que levam ao feriado e, portanto a compreensão da idéia de nação, fica prejudicada pela falta de referências dos não letrados sobre a data. Apenas aqueles que freqüentam a escola, partilham do conhecimento sobre os motivos dos feriados cívicos. A nação neste momento não se constitui, não se consolida. A identidade que se busca na construção dos heróis, não ganha consistência. Com isso os projetos de refundação da nação que estão sempre presentes em vários momentos, numa tentativa de criar uma tradição, não encontra o povo. É nesse ponto que se cria o hiato entre a memória das depoentes e os marcos de construção da identidade nacional.

As datas comemorativas servem de estratégia para a nação apresentar-se como parte e como todo ${ }^{15}$ compor o quadro de sua história, principalmente o lugar de memória que representam. No caso de Tiradentes, essa memória não atinge os não letrados ou em letramento, como mostraram as entrevistadas para essa pesquisa. O desconhecimento da figura de Tiradentes retirou o significado da comemoração e os motivos que sustentam a data como feriado nacional.

Quando o projeto de identidade nacional não atinge essas pessoas fica difícil definir o que é nação o que é ser brasileiro afinal onde estão as representações daqueles que são excluídos do projeto nacional de construção da nação. Em uma das entrevistas realizadas um elemento chama a atenção,

${ }^{15}$ SANDES, Noé Freire, op. cit. p.93. Aqui usamos um argumento de Sandes, que o utiliza para falar das comemorações em torno da independência do Brasil, realizadas pelo Império. 
a questão da liberdade, viver num país onde se tem liberdade que em outros não há. Outra questão diz respeito à natureza, neste território não tem terremoto e tudo que se planta dá. Nas falas das depoentes este sentimento de uma terra que é um Dom de Deus pelas maravilhas naturais é um dos poucos elos que poderíamos afirmar levam a algum sentimento de pertencimento ao lugar que chamam de Brasil.

O sentimento de nacionalidade, diríamos está marcado pelo trabalho, todas as entrevistadas são unânimes em afirmar que trabalharam muito e não tiveram medo do trabalho duro durante suas vidas. Num país marcado pelo patriarcalismo, e por relações que impediam a mulher de trabalhar fora de casa, as depoentes expuseram um país onde as mulheres trabalhavam tanto quanto os homens fora de casa e muito mais que os homens dentro de casa. Algumas assumiram a casa na ausência dos maridos.

É possivel reconstituir através dessas trajetórias um pouco da história das relações entre homens e mulheres no Brasil, uma relação mediada pelo mundo do trabalho e pelas dificuldades ligadas ao analfabetismo. Uma das questões que chama a atenção nas entrevistas é, por exemplo, as relações familiares, mediados pelas dificuldades financeiras homens e mulheres constroem relações pessoais que fogem aos padrões estabelecidos sobre os casamentos inclusive nas especificidades colocadas pela Bíblia, entre as maldições divinas que recaíram sobre homens e mulheres depois da perda do paraíso estão :

Ele o homem ganharás o pão com o suor do teu rosto e a ela multiplicará os sofrimentos de teu parto. Darás a luz com a dor a teus filhos; teus desejos te impelirão para o teu marido e tu estarás sob o seu domínio. ${ }^{16} 0$ trabalho fora do lar desde o final do século XIX era uma constante na vida das mulheres das classes populares, segundo Recenseamento da População do Império no Brasil em 1872, as mulheres representavam $78,3 \%$ da mão -de - obra fabril e $70 \%$ na prestação de serviço. ${ }^{17}$

Nos relatos apresentados pelas depoentes sobre os trabalhos que realizaram, mulheres que viveram em épocas diferentes, como dona Margarida

\footnotetext{
${ }^{16}$ Gênesis

17 REIS, Maria Cândida Delgado. Imagens Flutuantes: Mulher e Educação (São Paulo, 1910-30).Projeto História : Mulher e Educação Puc, São Paulo, 1981. p.47
} 
aos 73 anos, que teve suà vida produtiva nos anos 50 até Dona Nadir aos 46 anos, ainda trabalhando, em momento algum das entrevistas afirmaram que seus maridos a proibiram de trabalhar fora, ou que achassem isto errado, ou que os maridos tinham que sustentar a casa sozinhos. Não houve nenhum tipo de restrição por parte dos homens e nenhum tipo de constrangimento das mulheres, em exercerem durante suas vidas todo tipo de trabalho.

A relação com o trabalho talvez seja a mais significativa vertente de pertencimento a nação que apresentam as entrevistadas Em suas falas transparece a idéia de que são brasileiros dignos todos que trabalham e trabalhar é o que as identificam como um grupo. Seja o trabalho no campo ou na cidade. Desde sempre o que aprendem é que trabalhar é algo natural, o imaginário sobre o trabalho faz parte das representações construídas sobre o país.

As narrativas das mulheres entrevistadas demonstram a ligação que estabelecem desde cedo com o mundo do trabalho. Praticamente todas têm na necessidade de trabalhar o motivo principal para a ausência da escola. As representações que advem desta relação que estas mulheres estabelecem com o trabalho nos interessa principalmente as percepções sobre o mundo em que vivem. Os trabalhos que realizaram durante suas vidas servem de parâmetros de contagem do tempo e os sentidos da história.

o trabalho provocaria o despertar do entendimento do mundo, das interpretações sobre o as experiências humanas. Sendo que não podemos esquecer que o trabalho que nos que nos referimos aqui é o trabalho rural ou doméstico.

Se no caso dos conhecimentos a família tem papel fundamental, na questão das relações entre a memória e o trabalho há um rompimento da barreira do familiar, no momento que outros sujeitos como os peões, os camaradas entram em cena contribuindo para as visões de mundo que se formam no dia a dia. Como no caso de Dona Margarida ao relatar sobre Getúlio Vargas e o camarada que era apaixonado por Getúlio e dele contava muitas histórias, que ela se lembra e a ajudou no momento de compor um quadro na memória e falar sobre o periodo. Há também o trabalho doméstico nas casas dos patrões fazendeiros, a venda na fazenda e a circulação de pessoas.

Todas as entrevistadas sempre trabalharam e ajudaram a sustentar suas famílias. Mesmo depois de saírem do campo para cidade continuaram a exercer 
trabalhos remunerados, sem que 0 analfabetismo impedisse a procura e a contratação nos empregos, inclusive trabalhando em empresas públicas como no caso de Dona Tereza que por três anos trabalhou na Copel(Companhia de Eletricidade do Paraná)

Fui lá (na Copel) fiz uma ficha, isto é, levei uma ficha pronta que a minha vizinha fez para mim. Cheguei lá não precisou nem falar com a psicóloga, trabalhei dois anos e meio

Hoje Dona Tereza depois de exercer as funções de cozinheira em lanchonetes e restaurantes, trabalha em casa. Nesses trabalhos que exerceu Dona Tereza guarda a lembrança do trabalho duro e das dificuldades de não saber ler, quando veio o teste da Copel, não conseguiu passar e teve que sair do emprego, que gostava muito.

Dona Neuza hoje é salgadeira de uma grande rede de supermercados, já trabalhou em outros supermercados. Dona Izaudite depois da roça trabalhou, como doméstica e agora trabalha em casa. Dona Ermelinda trabalhou em restaurantes, fábricas e roupas e hoje trabalha como auxiliar de serviços gerais em um hospital da cidade. Dona Margarida trabalhou sempre na roça, já com os filhos crescidos veio para cidade, para ser dona de casa. No entanto o trabalho da roça consistia em mais do que simplesmente plantar ou colher era preciso decidir o que plantar, como comprar sementes, como guardar o dinheiro, como gastar o dinheiro, em suas palavras nóis sempre decidia junto, nóis dois trabalhava... trabalbava... nunca nóis pagou camarada.

As relações de trabalho, que demarcam um mundo alfabetizado, foram vivenciadas por mulheres que não sabiam ler e escrever, porém, enraizaram-se nesta sociedade e construíram suas vidas independentes dos contornos e da problemática que isto implicava.

Seriam válidas as afirmativas de exclusão social? Uma das características que impressionam nas narrativas dessas mulheres é o fato que a iniciativa dos estudos dá-se apenas após a criação dos filhos, a morte do marido, a aposentadoria. É o momento do descanso da vida produtiva que as leva aos estudos. 0 processo de estranhamento com o mundo letrado foi superado através do trabalho. 0 padrão de vida que adquiriram hoje todas com casa 
própria, algumas com carro e com os filhos estudados e até formados em faculdades coloca em questionamento algumas análises que relacionam diretamente baixos índices de desenvolvimento econômico e analfabetismo. Harvey Graff analisando sociedades industrializadas faz a seguinte afirmação:

Contrariamente à sabedoria popular ou acadêmica, passos importantes no intercâmbio, no comércio e mesmo na indústria ocorreram em alguns períodos e lugares com níveis notavelmente baixos de alfabetização, inversamente, níveis mais altos de alfabetização não mostraram ser estimulantes ou propulsores de desenvolvimento econômico "moderno." Is

A tese defendida por Harvey Graff é de que desde a revolução comercial até a revolução industrial na Europa, pouco se deve deste avanço econômico e tecnológico a alfabetização, pelo contrário afirma que a industrialização, com frequiência, reduziu oportunidades para a escolarização e, conseqüientemente, as taxas de alfabetização caíram à medida que ela cobrava seus direitos sobre o "capital bumano" de que se alimentava."

As pesquisas realizados por Graff, questionam os estudos que relacionam o desenvolvimento de sociedades pela ótica da alfabetização de seus indivíduos. Os impactos da alfabetização nos índices de desenvolvimento econômico, historicamente definido seriam demasiadamente insignificantes para serem justificados como tal.

A relação que se estabelece entre o alfabetismo e a cultura oral é mediada pela tensão em definir os modos de pensamento, de conbecimento e de expressão característicos dessas diferentes esferas culturais. ${ }^{20}$ São nos interstícios dessa mediação que se constroem as formas de pensar e aferir o mundo das mulheres entrevistadas.

Esta memória que transita entre o rural e o urbano, nos interessa a partir do momento que as tradições até então marcadamente oral sofrem concorrência com o escrito, no entanto, a perspectiva de desestruturação destas memórias

\footnotetext{
18 idem. P. 44

19) Idem. Ibdem, p. 44

${ }^{20}$ FILH 10, Luciano Mendes Faria. Representação da Escola e do Alfabetismo no século XIX. In. BATISTA, Antonio Augusto Gomes e GALVÃO, Ana Maria de Oliveira. (orgs) Leitura, práticas impressas e letramentos, Belo Horizonte, Autêntica, 1999., p.144.
} 
encontrariam nestas mulheres um elo enraizado na cultura oral devido ao analfabetismo. A forma como estabeleceram suas relações neste mundo letrado e construíram novas percepções sobre a sociedade, a natureza, o passado é parte do processo de formação da concepção de história que hoje apresentam.

As mulheres entrevistadas trabalharam desde a infância, o que dá sentido a suas vidas é o trabalho e a lembrança de quanto sofreram para criar os filhos e sobreviver, de quanto trabalharam sem tempo para estudar, namorar, viver assim como os velhos entrevistados por Ecléa Bosi²1 aquilo que fica é a sensação para todos de que apenas trabalharam e muito.

o projeto hegemônico de construção de uma memória nacional, não encontrou respaldo junto a pessoas que não sentem como sua a história construída pelos bustos nas praças e pelas festas cívicas, qual o motivo desse projeto de nacionalização não atingir essa população? As colocações das entrevistadas fazem pensar que este Brasil do qual estão falando não faz parte do seu mundo, ausente do dia a dia de seu trabalho, de suas trajetórias de vida.

Certamente que suas histórias ao referirem-se aos seus mundos compõe o quadro da história brasileira, mesmo nas ausências que as impedem de vislumbrarem o país onde vivem é possível perceber, que os nós que as fazem un coletivo e dizem respeito a uma história de dor e trabalho.

Quando falam da história nacional é como se falassem de um estranho, ausente e desconhecido, que não compartilha das suas vidas. Demonstram o distanciamento imposto entre sua vida e a história do país, um tempo também vivido por todas, no entanto, não compartilhado com os rumos da nação onde viveram e vivem, as formas como se referem aos acontecimentos é de fora, como observadoras e não como participantes.

Provavelmente porque a história do Brasil seja para a maioria dos brasileiros, apenas objeto dos currículos escolares, sendo assim para as entrevistadas o conhecimento sobre a história do Brasil só seria possível com o estudo, várias vezes afirmaram: pois é, se a gente tivesse estudado, sabia responder, nãa é mesmo.? Estaria a apropriação desse conhecimento restrito apenas a escola? A História do Brasil seria apenas uma história para os livros e para os letrados?

${ }^{21}$ BOSI, ÉCLEA op .cit 
Nos retratos transmitidos pelas narrativas podemos perceber que existe outra história do Brasil que poderia ser contada tendo como fonte a trajetória de cada uma e as percepções que construíram sobre o mundo em que vivem. Uma história em que partilharam as experiências da migração em tempos dificeis, em que trabalharam, sofreram foram felizes, o distanciamento que guardam do país onde vivem indica que as escolhas que incidiram na construção desta 11 ação deixaram de fora grande parte da população, que não se reconhecem nos heróis, nas datas comemorativas, nas festas em que a nação reitera seus mitos. A quem seriam destinados as preocupações daqueles que se debruçam em criar um imaginário para a nação? Arriscamos afirmar que possivelmente a memória sobre a nação é negada por ser uma memória projetada por um determinado grupo social. Seria o Ricoeur chama de trabalho do esquecimento. A negação de uma memória social comum para a nação teria o objetivo de confrontar uma identidade que as exclui.

Bibliografia

BOSI, Ecléd. Memória e Sociedade. Lembranças de velhos, São Paulo: Queiroz Editor, 1983.

CARVLLHO, José Murilo. A formação das Almas São Paulo, Companhia das Letras, 1990.

FILH(), Luciano Mendes Faria. Representação da Escola e do Alfabetismo no século XIX. In. BATISTA, Antonio Augusto Gomes e GALVÃO, Ana Maria de Oliveira. (orgs) Leitura, práticas impressas e letramentos, Belo Horizonte, Autêntica, 1999.,

FONSECA, Thaís Nívea. História e Ensino de História, Belo horizonte Autênctica, 2003

HALBWACHS, Maurice. A memória coletiva, São Paulo, Vértice, 1990.

PILET'TI, Nelson e PILETTI, Claudino, História e Vida. 11ª ed. São Paulo, Ática, 1997.

REIS, Maria Cândida Delgado. Imagens Flutuantes: Mulher e Educação (São Paulo, 1910-30).Projeto História: Mulber e Educação Puc, São Paulo, 1981.

SALIBA, Elias Tomé As imagens canônicas e o ensino de História. IN.SCHIMDT „Maria Auxiliadora e CAINELLI, Marlene Rosa. III Encontro Perspectivas do Ensino de História. Curitiba. Aos QuatroVentos, 1999.

SANDES, Noé. A invenção da nação - entre a monarquia e a república. Goiânia, Editora da UFG, 2000 . 


\section{The construction of the heroes and the national memory among the not learned}

\section{ABSTRACT}

It is intended in this article to discuss the implications concerning the analyses about memory and the constitution of the national heroes. Tends as presupposition the studies about the history teaching and the construction of the national memory, we intended to lift some relative subjects the presence of the icons of the national history among people that didn't frequent the formal school. In that research we interviewed women of a course of popular literacy, on Tiradentes's illustration (national holiday) and other civic parties, and Tiradentes is considered by many historians as present in the collective memory of the nation as a national hero.

Key words: history teaching, memory, popular education. 